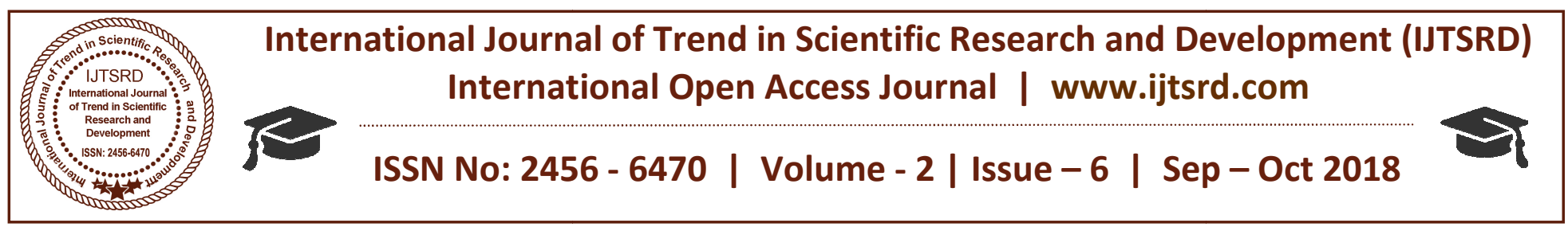

\title{
Aqua Silencer
}

\author{
Batta Mahesh \\ Student, Sanskrithi School of Engineering, Puttaparthi, Andhra Pradesh, India
}

\section{ABSTRACT}

Global warming is increasing on our earth due to major increase in the pollution. Air pollution is very serious on our earth. So it is required to solve these problems by taking various serious attempts. Hence to reduce these pollutants from Exhaust of Engine a new technology is introduced called Aqua silencer. Sound produced under water is less hearable than it produced in atmosphere. This mainly because of small sprockets in water molecules, which lowers its amplitude thus, lowers the sound level. Because of this property water is used in this silencer and hence its name AQUA SILENCER. Aqua Silencer is a modified version of a conventional silencer aimed at the reduction of toxic emission. Aqua silencer is one of the attempt taken in reduce the air pollution. It is fitted to the exhaust pipe of engine or system. These Silencers is used to reduce the noise and control the emission of dangerous gases. An aqua silencer is an attempt in this direction which is mainly dealing with control of emission and noise. . The aqua silencer system is design for replace commonly used single unit silencers in engine with its slender structure and less weight.

Keyword: Pollution Free, Charcoal Layer, Perforated tube

\section{INTRODUCTION}

The aqua silencer reduces emission noise because, the sound produced in aqua silencer under water having less amplitude than the sound produced in open atmosphere .These is happen because of in water molecules there are small sprockets which lowers amplitude of emission gases and lower the sound level. In Aqua silencer the main component perforated tube which consists of number of different diameter holes. Generally these are 4 set of holes on perforated tube. The charcoal layer which is pasted over perforated tube can control the emission using the activated charcoal and highly porous extra free valences so these layer having high absorption capacity. It control the noise \& emission in an ic engine. It is fitted at the exhaust of the pipe; sound produced under water is less hearable than sound produced in the atmosphere.

The emission of gases can be controlled by using the activated charcoal layer $\&$ lime water. The noise and smoke level is considerably less than the conventional silencer; there's no need of a catalytic converter and it is easy to install. In this silencer, the Charcoal and Water is used so it is called hybrid aqua silencer, and it is useful in automobile, industry, DG sets \& DG machines, Marin and Boats also so, it is known as hybrid universal aqua silencer. Aqua silencer is easy to install and there is no need of catalytic converter. Aqua silencer is one of the important methods for effective reduction of toxic gases and noise.

The pollutants formed in engine exhaust are,

Carbon monoxide $(\mathrm{CO})$

$>$ Carbon dioxide $(\mathrm{CO} 2)$

$>$ Oxides of Nitrogen (NOx)

$>$ Sulphur dioxide(SO2)

> Particulate and Unburned Hydrocarbons (UBHC)

$>$ Respirable combustible Dust (RCD)

The above polluting contents in the engine exhaust are to be controlled by the Aqua Silencer.

\section{COMPONENTS:}

$>$ Perforated Tube.

$>$ Charcoal Layer.

$>$ Outer Shell.

$>$ Non Return Valve.

$>$ Flange.

$>$ Drain plug

\section{Perforated tube:}

It is a tube with different diameters. The purpose of these holes on the tube is to break down the large 
mass of gas entering, into smaller ones. This perforated tube is attached to the exhaust of the engine. The other end of the perforated tube is closed by plug.

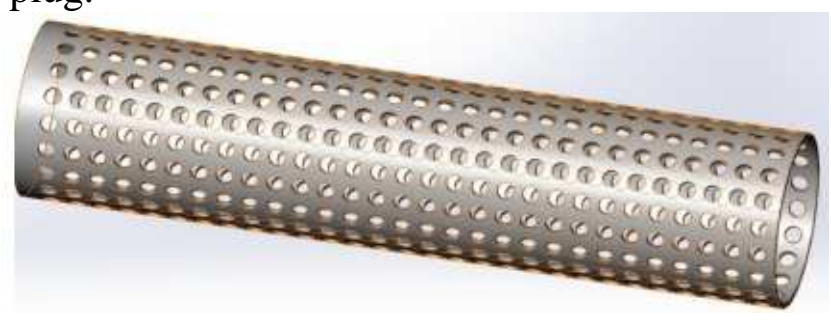

\section{Charcoal Layer:}

The charcoal layer is fixed over the perforated tube, these charcoal layer has more absorbing capability because it has more surface area. It is called as ACTIVATED CHARCOAL and it is produced by heating the charcoal above 1500 oc for several hours in a burner due to which its surface area gets increased.

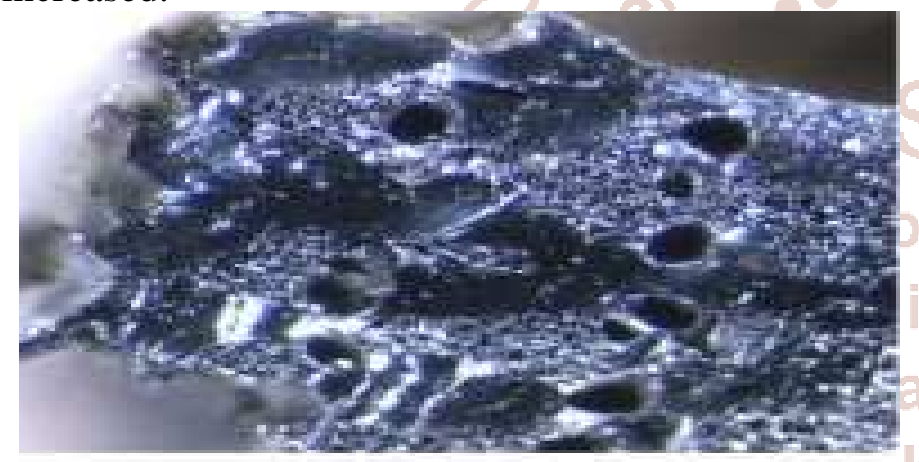

\section{Outer Shell:}

In outer shell the whole set up is kept inside. It is mainly made up of steel or iron. water outlet, inlet also the exhaust tube was provide in there shell itself.

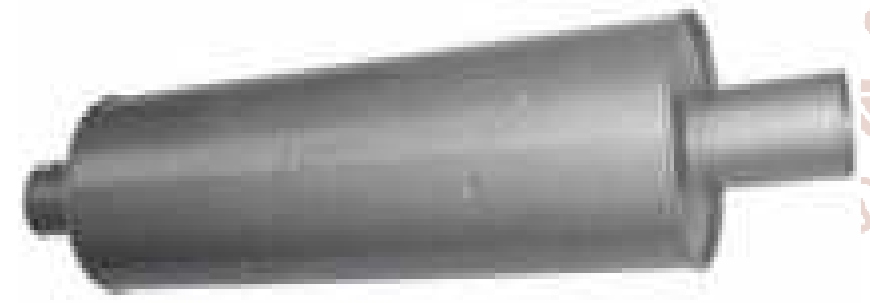

\section{Non Return valve:}

A non-return valve allows a medium to flow in only one direction. ... A non-return valve can be fitted to ensure that a medium flows through a pipe in the right direction, where pressure conditions may otherwise cause reversed flow.

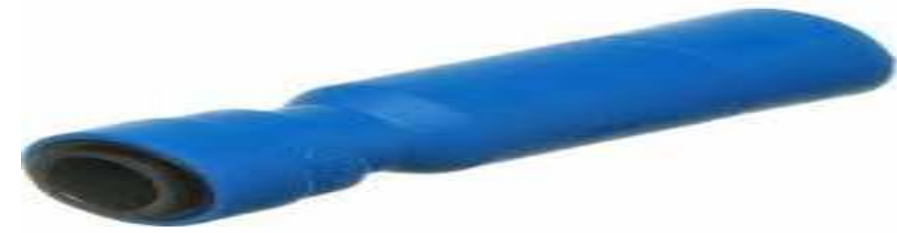

\section{Flange}

A flange joint is a connection of pipes, where the connecting pieces have flanges by which the parts are bolted together. Although the word flange generally refers to the actual raised rim or lip of a fitting, many flanged plumbing fittings are themselves known as flange.

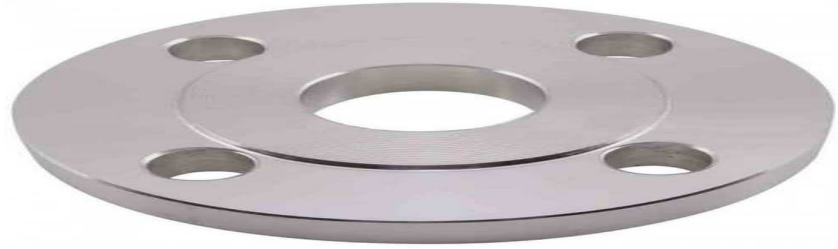

\section{Drain plug:}

A drain plug is a plug which is taken out to allow a fluid to be drained from a tank which is fitted at the bottom of the tank.

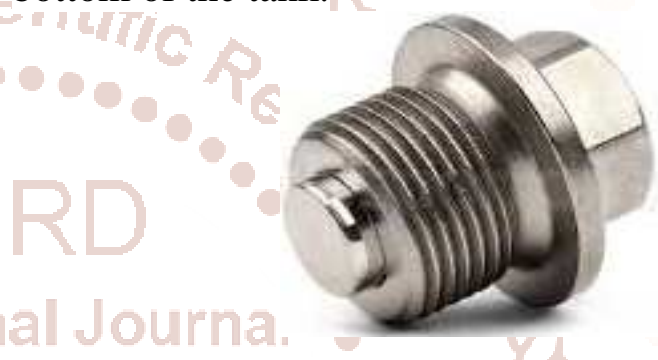

\section{Working principle:}

The exhaust gases from engine enters from inlet to aqua silencer then perforated tube convert high mass of bubble to the low mass of bubbles. Then this gases passes through charcoal layer which again purify the gas. This charcoal layer is highly porous and possess extra free valence so it having high absorption capacity. During that gases get contact with lime water they chemically react with it. The charcoal layer is covered with outer shell which is filled with water due to that emission noise is reduces. The sound produced in the water having less amplitude than the sound produced at atmosphere. It happen because of water molecule which lower its amplitude. After passing over charcoal layer some of the gases may be get dissolved into the water. Finally exhaust gases escape through opening at the top of container into the atmosphere hence from above working principle aqua silencer reduces noise and pollution.

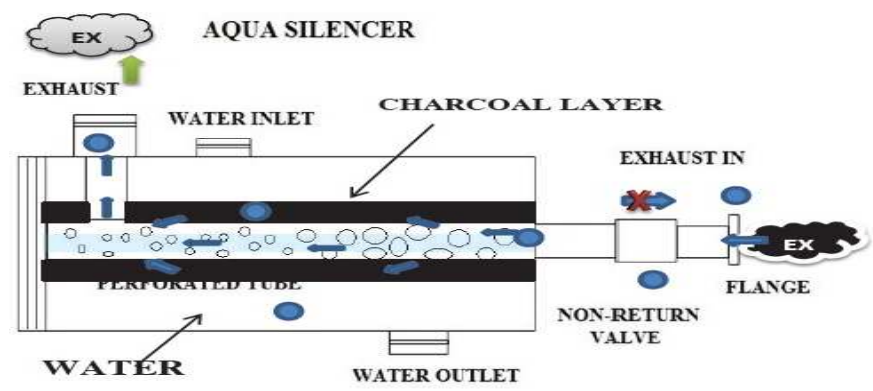




\section{Chemical Reactions:}

$\mathrm{Ca}(\mathrm{OH}) 2+2 \mathrm{HNO} 2=\mathrm{Ca}(\mathrm{NO2}) 2+2 \mathrm{H} 2 \mathrm{O}$

$\mathrm{Ca}(\mathrm{OH}) 2+2 \mathrm{HNO3} \mathrm{Ca}(\mathrm{No3}) 2=2 \mathrm{H} 2 \mathrm{O}$

When the carbon-di-oxide present in the exhaust gas comes in contact with the limewater, calcium carbonate will precipitate. The calcium carbonate when further exposed to carbon-dioxide, calcium-bicarbonate will be precipitated. The following is the chemical reaction.

\section{$\mathrm{Ca}(\mathrm{OH}) 2+\mathrm{SO} 2=\mathrm{CaSO} 3+\mathrm{H} 2 \mathrm{O}$}

From calcium carbonate, calcium sulphite will precipitate and $\mathrm{CO} 2$ will be by-product. Because of the small percentage and $\mathrm{SO} 2$ presence, the liberation of Carbon dioxide is very less. But the liberated $\mathrm{CO} 2$ will again combine with $\mathrm{CaCO} 3$ to form calcium bicarbonate.

\section{Merits:}

$>$ No vibration when the engine is running.

$>$ Cost is reduced 60 to $70 \%$ compared to ordinary silencer.

$>$ Sound is reduced

$>$ Low cost

$>$ Start the engine easy.

$>$ Control emission and noise in greater level.

$>$ Carbon is precipitated.

\section{Demerits:}

$>$ Lime water filling is required once in a year.
$>$ Silencer weight is more comparing to conventional silencer.

Additional space is required.

\section{Applications:}

$>$ It is used in marine \& boats.

$>$ It is applicable for DG sets \& DG machine.

$>$ It is used in industrial sector.

$>$ It is also used in automobile sector

\section{Conclusion:}

The aqua silencer is more effective in the reduction of emission gases from the engine exhaust using perforated tube, lime water and charcoal. By using perforated tube the back pressure will remain constant and the sound level is reduced. By using perforated tube the fuel consumption remains same as conventional system by using water as a medium the sound can be lowered and also by using activated charcoal in water we can control the exhaust emission to a greater level. Due to use of water as a medium sound reduces these system having pollution free emission and smokeless. These system is very cheap. These system is used for both four wheelers and two wheelers. It plays important role in industries.

\section{References:}

1. http://www.123seminarsonly.com/ME/AquaSilencer.html

2. https://www.slideshare.net/SonyJoseph13/aquasilencer

3. https://www.youtube.com/watch?v=h7TmEVsIjJ0

4. https://www.quora.com/What-is-aqua-silencer 